\title{
The Synthesis of the Student Relationship Management System Using the Internet of Things to Collect the Digital Footprint for Higher Education Institutions
}

\author{
https://doi.org/10.3991/ijoe.v15i06.10173 \\ Nualsri Songsom $(\bowtie)$, \\ King Mongkut's University of Technology, Bangkok, Thailand \\ nuasri sonedusit.ac.th \\ Prachyanun Nilsook \\ Vocational Education Technology Research Centre \\ King Mongkut's University of Technology, Bangkok, Thailand \\ Panita Wannapiroon \\ Innovation and Technology Management Research Centre \\ King Mongkut's University of Technology, Bangkok, Thailand
}

\begin{abstract}
The purpose of this research was to synthesize and to evaluate the elements of the student relationship management system using the internet of things to collect the digital footprint for higher education institutions. The results of the research showed that the student relationship management system using the internet of things had five elements, which were: 1) identify module; 2) alert module; 3) tracking module; 4) SRM module and 5) analytic module. The evaluation result of the student relationship management system using the internet of things to collect the digital footprint for higher education institutions had overall appropriateness at a very high level and the overall appropriateness of usability result at a very high level.
\end{abstract}

Keywords-Student relationship management, internet of things, digital footprint

\section{Introduction}

Students are considered to be the centre of an education institution. Therefore, universities value the importance of their students. In some countries, learning experience outside the classroom is considered more important. Since the mid-twentieth century, concerns about a wider learning experience outside the classroom and the expansion of university education, which has started in many countries, has raised the number and variety of students. Thus, the university must understand the nature of student mental health and society, which play an important role in the student's academic achievement. Therefore, the concept and direction for the development of students and student affairs must be defined [1], as we know that current technology 
brings knowledge and learning to society [2]. Information systems used in higher education institutions may support the process of academic management, such as registration, management, etc. However, the system does not allow close monitoring of the student's academic activities, including the evaluation of academic performance and learning support. On the other hand, we must accept that, in order to manage student relationships, activities and support for academic performance, it must be monitored at all times [3]. Finding a modern tool that is appropriate within the information technology (ICT) age as it now has such an important role with our lifestyle is very important [4]. At present, the internet of things has the ability to connect devices extensively and has brought development that leads to an intelligent city and also more healthy applications [5]. The internet of things (IoT) is a concept that collects, verifies and manages information in real time by connecting to large Internet networks and linking between devices as well as people. Therefore, the Internet network would provide such services including: connecting, managing, recognizing and controlling the communication between people and objects [6]. In the digital age, we now live two sorts of lives, either online and offline. Our digital path is built from our interactions and behaviour in the digital environment, with our digital footprint as the key component [7].

One of the first steps, which need to be taken to create an innovation in student services, is to change the viewpoint. The innovation will not only change the services' methods and their rationale, but also the method of service delivery to ensure prompt access. Higher education institutions must adopt the viewpoint that students are at the centre of interactions [8]. However, with the integration of online social networks and IoT infrastructure, as well as the popularity of Smartphones, identification using behaviour when accessing online social networks is now a new and emerging concept [9]. The prediction of the attributes and preferences of each user can be used to improve products and services [10]. Higher education institutions should give priority to the construction of the internet network infrastructure and the preparation of appropriate technology, which will make the most impact [11,12]. Analysis of student behaviour can be used as the reference point of the university's effectiveness. It can also be used to foster organizational culture and manage student lives [13]. The mentioned background and significance of the research question prompted the researchers to study the conceptual framework of student relationship management using the internet of things to collect a digital footprint for higher education institutions.

\section{$2 \quad$ Literature Reviews}

\subsection{Student relationship management}

Customer Relationship Management (CRM) is currently widely known around the globe but, for higher education institutions or universities, which are not commercial institutions, in order to earn the customer's trust, the relationship between the institutions and the students must be managed [3]. The purposes of the adaptation of the CRM concept to higher education institutions are to: 
- Build inbound and outbound connections with customers (students)

- Create satisfaction and loyalty among customers (students)

- Attract new customers (students)

- Create a competitive edge

- Retain both new and existing customers (students) [14]

Therefore, universities adopted the student relationship management (SRM) concept in order to improve the quality of the learning process and activities of the students [15]. While there is a lot of research that focuses on CRM, only a small portion deals directly with SRM in the context of the field of education. As a result, there is not enough technological support for SRM in universities. For example, SRM system architecture should be proposed to support the concept and SRM techniques should be introduced to aid the university's business intelligence [3].

Using information technology and communication can help to maintain a close relationship with customers, which is beneficial for the organization [16]. The key to CRM is to design a communication and IT support channel for front desk and other customer contact points. As for direction setting for the higher educational market, CRM strategies and implementation must be adapted to the specific context. However, as SRM is a set of activities designed to create and maintain the relationship with students $[16,17]$, the strategy for customer relationship management will differ according to the types of customers, depending on their positions in the customer life cycle, starting from initiating the relationship with prospects, retaining existing customers and rebuilding the relationship with lost customers [16,17]. SRM is a tool that promotes learning as part of sustainable development, especially in higher education, which has become increasingly demanding [18]. There are risks in using SRM. If the university does not use it properly, the ultimate purpose cannot be achieved. In order to use SRM effectively, an appropriate tool is required, including the methods to realize the concept of student relationship management comprehensively and systematically. Although currently there is little research supporting the hypothesis that SRM induces risk, the issues should be considered while managing the university [18].

\subsection{The Internet of things}

The internet of things (IoT) is the network of physical objects or "things" embedded in electronic devices, software and sensors. Connecting these objects to the network will allow them to collect and exchange information. IoT allows the objects to perceive and to be controlled by the existing network infrastructure. It creates the chance of integration between physical objects and computer system, resulting in effectiveness and accuracy, as well as generating economic benefit. All devices can be identified using an embedded computer system, but they must work together under an Internet-enabled infrastructure. Experts have forecasted that IoT will contain over 50 billion objects by 2020 [19]. A British technology pioneer, Kevin Ashton, introduced the concept of IoT as a network of objects, which are globally interconnected by embedded rfid in 1999 while working at Auto-ID Lab, formerly known as Auto-ID Center. Generally, IoT is the more advanced connection of devices, systems and ser- 
vices than machine-to-machine (M2M) communication and it covers various protocols, domains and applications [19]. The digital technology platform is the basis of digital business and it must have access to the digital system. Every organization has five technology platforms: the information system, customer experience, analysis and intelligence, as well as news and information, IoT and business ecosystem platforms [20]. The elements of IoT are: A. identification; B. sensor; C. communication; D. calculation; E. service and F. semantics [21]. IoT promotes changes in education, learning, teaching, managing, experimenting and training in education institutions, etc. Currently, IoT is initiating an education revolution as it collects, verifies and manages data in real time while connecting to the larger Internet network, connecting between objects and connecting to people. Therefore, the Internet network will provide the connection, management, perception and control between people and objects [6]. The various methods and technologies used to develop the monitoring systems are as follows:

RFID (Radio-frequency identification) is an automatic-identification method. Personal information is stored in an electronic device called a RFID Tag (signal generator) and is retrieved by a RFID reader (interrogator) using radio frequency [22]. The attendance management system is employed to control and check students [23]. The technology, which is used to monitor and check students in schools, is RFID and IoT. The system uses RFID technology to monitor the student's activities and track the location of the students within the school's premises, allowing parties with different access rights, including parents, system administrators and school bus drivers, to keep track of the students at all times. Activities and movement of students can be monitored and tracked by parents, school management and drivers at specified levels [19].

BLE (Bluetooth Low Energy) is a wireless technology, which allows Smartphone applications to identify the exact location of students, both indoor and outdoor, with high accuracy. The signal from a beacon can be used to trigger the application to send notifications specific to the time and location. The beacon is a small and inexpensive device that uses battery power. Currently, beacon technology is widely adopted in various businesses, including retail, entertainment, reception, transportation, health care, outdoor media, and in private locations [24]. The beacon developed mobile phone applications and servers, which are used to monitor activity or attendance of a class with more than 1,000 participants. Moreover, if the participants choose to attend different activities, they do not have to register again because their personal information has already been saved to their mobile phone application [25].

\subsection{Student affairs}

UNESCO has been assigned to study student affairs and the International Association of Student Affairs and Services Professionals (IASASP) has specified the desired outcomes of student affairs operation in higher education institutions as follows:

- A high quality, well-rounded greater learning experience;

- Improved higher education access regardless of ability/background; 
- Better retention and progress toward graduation

- Increased graduation rate

- Enhanced career/employment prospects

- Sustainable interest in lifelong learning

- A life as a responsible, contributing community member and citizen [1].

University life is complex and students must adapt to classes and strive to achieve a good academic result, which is very time and energy consuming. Factors include, for example, extra-curriculum activities, a hectic social life, the need to get a job because of financial pressure, being a member of a new club with a small number of members, communication with friends and family, endeavoring to be both physically and mentally healthy while facing increasing and decreasing workloads and obligations, etc. Therefore, it is considered a challenge to succeed in such environment [26]. There are many things relating to the student's life, which need to be considered.

Firstly, to fully understand student life, their Smartphones are automatically and continuously inspected to evaluate their mental health, academic performance and behavioral trends.

Secondly, analysis to learn about the relationship between information from automatic detection and the set of health measures.

Thirdly, to observe the trends in the student lifecycle as it shows that the student's positive attitude and conversation levels, low stress, healthy sleep and daily activity patterns are starting to be affected [27].

\subsection{Digital footprint}

A digital footprint is the trace of information left by digital service users [28]. The process of creating the "digital footprint" depends on a structured approach, which combines input (collection) and output (value), with a feedback loop that controls the whole process. The feedback loop will gradually increase the value and adjust the outcome (value). The process starts from analyzing data gathered from various sources (focusing on the digital footprint) to generate value. The outcome is called 'behavioural DNA' and it provides a detailed description of the person [29]. As a result of the popularity of mobile phones with sensors, impressive growth in the number of Internet network and social network users, the use of the sensor network in public buildings, facilities, private premises and the outdoor environment, the "digital footprint" left by users while interacting with their physical space in the cyber world has been accumulating continuously [30]. When the current university students are accepted and join the campus, they will leave a unique digital footprint in the university's IT system. A student's digital footprint includes:

- Demographic data

- Academic records

- Assignments and test results

- Library access and borrow \& return history and 5) access to WiFi or other networks [31]. 


\subsection{Student services}

One of the first steps to create innovation in student services is to change the viewpoint of the services by, not only rethinking why the services exist, but also how the services are provided. The viewpoint has shifted so that students are the centre of all interactions [8]. A boarding school (BS) is a school where students study and live within the school premises. The school provides various extra-curriculum activities, which support learning, as well as good facilities, including computer labs, and gym and entertainment rooms, which help the students to relax and enhance their brain development. One of the common problems for BS management is that they use outdated systems, which cannot check the location of the students. The application of a RFID Metric Card system to the school monitoring system is an improvement for the school management process because it introduces the automatic detection of the movement of the target group and it enhances the safety of the students [22].Community services in universities can be enabled by analyzing data collected from sensors in personal mobile phones, GPS of public buses, WiFi or Bluetooth connecting points in the building, the relationship on the social network, etc. [30] [30]. The development of innovation in education institutions should align with key trends, which are:

- Image and branding

- Creating and changing sustainably

- Lifelong relationship

- Technologies for supporting and improving student/customer experience [8].

\subsection{Student behaviour}

Every time a user retrieves a webpage, lots of data is generated in the form of log files. Analyzing such log files will allow us to understand user behaviour [32]. The behaviour would be different, depending on event and time and it can be observed from mobile phone usage data stored in the mobile phone's log files [33]. However, the integration of social networks to IoT infrastructure, as well as the popularity of mobile devices, plays an important role in establishing identification, which is the basis of the behaviour exhibited when using social networks, resulting in a new concept [9]. The prediction of attributes and preferences of each user can be used to improve products and services [10]. Student behaviour analysis can be used as a reference of the university's effectiveness. It can also be used to foster organizational culture and manage the lives of the student [11].

The conceptual framework of student relationship management system using the internet of things to collect the digital footprint for higher education institutions as shown in Figure 1.

Figure 1 shows the conceptual framework of student relationship management system using the internet of things to collect the digital footprint for higher education institutions. 


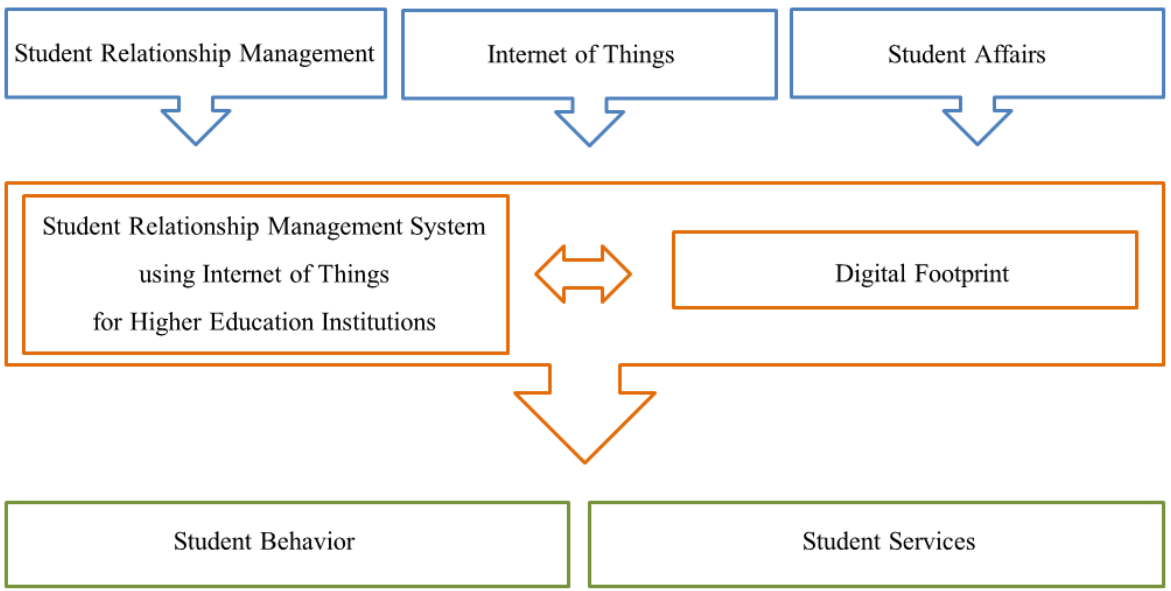

Fig. 1. The conceptual framework of student relationship management system using the internet of things to collect the digital footprint for higher education institutions.

\section{$3 \quad$ Research Objectives}

Our research objectives were as follows:

- To synthesize the elements of the student relationship management system using the internet of things to collect the digital footprints for higher education institutions.

- To design the elements of the student relationship management system using the internet of things to collect digital footprints for higher education institutions.

- To evaluate the elements and usability of the student relationship management system using the internet of things to collect the digital footprints for higher education institutions.

\section{$4 \quad$ Research Methodology}

The research was conducted in three phases as follows:

Phase 1: The synthesis of the elements of the student relationship management system using the internet of things to collect the digital footprints for higher education institutions by reviewing documents, literature and related research, including the following references: [16], [22], [34], [35], [36], [37], [38], [39], [40], [41].

Phase 2: The designing of the element diagram of the student relationship management system using the internet of things to collect the digital footprint for higher education institutions. The research instruments for this phase were: 1) the element diagram of the student relationship management system using the internet of things to collect the digital footprint for higher education institutions and 2) the suitability evaluation form of the designed element diagram. 
Phase 3: The evaluation of the student relationship management system using the internet of things to collect the digital footprint for higher education institutions by ten experts who had experience in the field of student relationship management (SRM), the internet of things (IoT) and information and communication technology (ICT) using purposive method.

\section{$5 \quad$ Results}

The synthesis of the elements of the student relationship management system using the internet of things to collect the digital footprint for higher education institutions are shown in Table 1

Table 1. The synthesis of the elements of the student relationship management system using the internet of things to collect digital footprint for higher education institutions.

\begin{tabular}{|c|c|c|c|c|c|c|c|c|c|c|}
\hline \multicolumn{11}{|c|}{ Research } \\
\hline \begin{tabular}{|c} 
Student \\
Relationship \\
Management \\
System using \\
the \\
Internet of \\
Things
\end{tabular} & $\begin{array}{c}\text { Maria, } \\
\text { Mari- } \\
\text { bel [16] }\end{array}$ & $\begin{array}{c}\text { Herdawatie } \\
\text {, Mohd., } \\
\text { Zarina } \\
\text { Mohd. and } \\
\text { Mohd.[22] }\end{array}$ & $\begin{array}{c}\text { Melissa, } \\
\text { Jonice, } \\
\text { Jano M } \\
{[34]}\end{array}$ & $\begin{array}{c}\text { Ji- } \\
\text { rapong, } \\
\text { Sakchai } \\
{[35]}\end{array}$ & $\begin{array}{c}\text { Sahoo } \\
{[36]}\end{array}$ & \begin{tabular}{|} 
Srinivas, \\
Prashant \\
h, \\
Sundara- \\
vadanam, \\
Ma- \\
heshwar, \\
Prasanna \\
and \\
Vara- \\
lakshmi \\
[37]
\end{tabular} & \begin{tabular}{|c|} 
Mboun \\
gouu \\
[38]
\end{tabular} & \begin{tabular}{|c|} 
Bozidar, \\
Marijana, \\
Zorica, \\
Alesksan- \\
dra, Milos \\
{$[39]$} \\
\end{tabular} & $\begin{array}{c}\text { Jiten- } \\
\text { dra, } \\
\text { Hyung- } \\
\text { il, } \\
\text { Meena, } \\
\text { Ashish, } \\
\text { Danish } \\
\text { [40] }\end{array}$ & $\begin{array}{l}\text { Ab- } \\
\text { dul, } \\
\text { Jyoth } \\
\text { i [41] }\end{array}$ \\
\hline $\begin{array}{l}\text { Identify } \\
\text { Module }\end{array}$ & $\checkmark$ & $\checkmark$ & $\checkmark$ & $\checkmark$ & $\checkmark$ & $\checkmark$ & & $\checkmark$ & $\checkmark$ & $\checkmark$ \\
\hline Alert Module & $\checkmark$ & & $\checkmark$ & $\checkmark$ & & & & $\checkmark$ & $\checkmark$ & \\
\hline $\begin{array}{l}\text { Tracking } \\
\text { Module }\end{array}$ & & $\checkmark$ & $\checkmark$ & $\checkmark$ & $\checkmark$ & $\checkmark$ & $\checkmark$ & $\checkmark$ & & $\checkmark$ \\
\hline SRM Module & & $\checkmark$ & $\checkmark$ & $\checkmark$ & & $\checkmark$ & & & $\checkmark$ & $\checkmark$ \\
\hline $\begin{array}{l}\text { Analytic } \\
\text { Module }\end{array}$ & $\checkmark$ & & $\checkmark$ & $\checkmark$ & & & $\checkmark$ & & & \\
\hline
\end{tabular}

According to Table 1, the synthesis of the elements of the student relationship management system using the internet of things to collect the digital footprint for higher education institutions consisted of five elements:

- Identify module

- Alert module

- Tracking module

- SRM module

- Analytic module

The design of the element diagram of the student relationship management system using the internet of things to collect the digital footprint for higher education institutions is shown in Figure 2. 


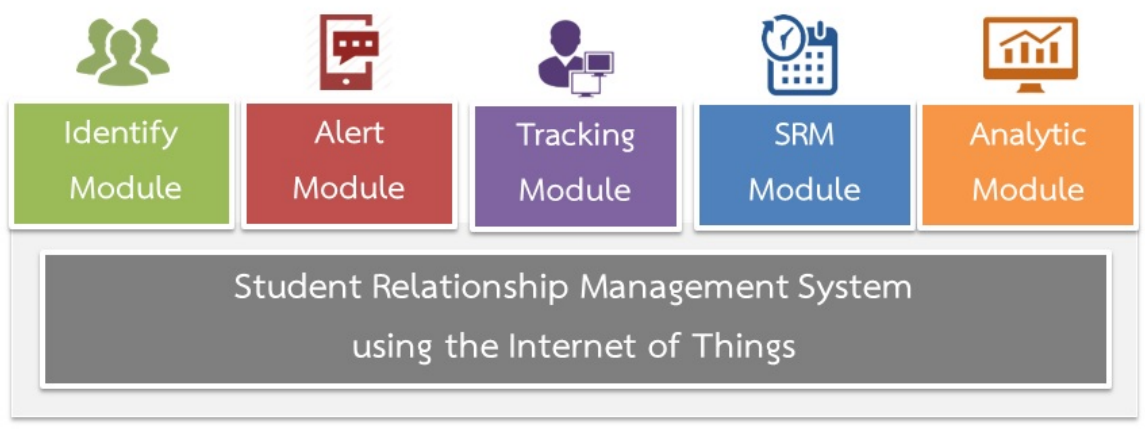

Fig. 2. The element diagram of the student relationship management system using the internet of things to collect the digital footprint for higher education institutions.

According to Figure 2, the element diagram of the student relationship management system using the internet of things to collect the digital footprint for higher education institutions consisted of five elements as follows:

Identify Module is the module that interacts directly with the users. This module works when the user passes the sensor spot, the system will send user data to the database and identify the information regarding the user.

Alert Module is the module that will send alert messages or notifications for users to interact with the system.

Tracking Module is the module that stores the usage data when users have passed the system devices.

SRM Module is the module that will send the information to the users by managing the data that is sent from the sensor spot according to the individual requirement and will be repeatedly updated when usage has been detected.

Analytic Module is the module that analyzes the data stored in the system and will be reported as a conclusion result for people who officiate in management who make the relevant decisions.

The evaluation of the student relationship management system using the internet of things to collect the digital footprint for higher education institutions is shown in Tables 2 and 3.

Table 2. The evaluation of the student relationship management system using the internet of things to collect the digital footprint for higher education institutions.

\begin{tabular}{|l|c|c|c|}
\hline \multicolumn{1}{|c|}{ List of Evaluation } & $\overline{\boldsymbol{x}}$ & S.D. & Level of appropriateness \\
\hline Identify Module & 5.00 & 0.00 & very high \\
\hline Alert Module & 5.00 & 0.00 & very high \\
\hline Tracking Module & 5.00 & 0.00 & very high \\
\hline SRM Module & 4.50 & 0.71 & very high \\
\hline Analytic Module & 5.00 & 0.00 & very high \\
\hline Total & 4.90 & 0.14 & very high \\
\hline
\end{tabular}

According to Table 2, the overall evaluation result of the student relationship management system using the internet of things to collect the digital footprint for higher 
education institutions was at a very high appropriate level $(\bar{x}=4.90$, S.D. $=0.14)$. Considering each item, every item was at a very high appropriate level.

Table 3. The usability evaluation of the student relationship management system using the internet of things to collect digital footprint for higher education institutions.

\begin{tabular}{|l|c|c|c|}
\hline \multicolumn{1}{|c|}{ List of Evaluation } & $\overline{\boldsymbol{x}}$ & S.D. & Level of appropriateness \\
\hline The suitability of IoT devices in terms of supporting the system & 5.00 & 0.00 & very high \\
\hline The suitability of digital footprint management & 5.00 & 0.00 & very high \\
\hline The system performance & 4.50 & 0.71 & very high \\
\hline The suitability for implementation & 5.00 & 0.00 & very high \\
\hline Total & 4.88 & 0.18 & very high \\
\hline
\end{tabular}

According to Table 3, the overall usability evaluation result of the student relationship management system using the internet of things to collect the digital footprint for higher education institutions was at a very high appropriate level ( $\bar{x}=4.88$, S.D. $=$ $0.18)$. Considering each item, every item was at a very high appropriate level.

\section{Conclusion and Discussion}

According to our evaluation results of the student relationship management system using the internet of things to collect the digital footprint for higher education institutions, had an overall appropriateness at a very high level and the overall appropriateness of usability result was at a very high level, which showed that the experts had consistent opinions. As shown in the synthesis result, the student relationship management system using the internet of things to collect the digital footprint for higher education institutions consisted of five modules including: the identify module, alert module, tracking module, SRM module and analytic module.

The identify module is the module that interacts directly with the users, sends user data to the database and identifies the information regarding the user, which is in accordance with Sahoo, who stated that the identify module will receive the data from an authorized user for authentication and proceed to the next step within the application [36].

The alert module is the module that sends alert messages or notifications for users to interact with the system, which is in accordance with Jirapong and Sakchai, who stated that the alert module is there to provide information to the users [35].

The tracking module is the module that stores the usage data when users have passed the system devices, which is in accordance with Mboungou, who stated that the tracking module was used for managing and tracking campaigns for the target group [38].

The SRM module is the module that sends the information to the users by managing the data that is sent from the sensor spot according to the individual requirements and will be repeatedly updated when usage has been detected, which is in accordance with Bozidar, who stated that the SRM module can automatically send individual information about the learning activities to the users [39]. 
The analytic module is the module that analyzes data and can be used by people who officiate in management and make the relevant decisions, which is in accordance with Mboungou, who stated that the analytic module provides user and transaction data analysis in order to improve the relationship with customers [38]. In terms of implementation, there should be more research on the context of higher education institutions management for effective and appropriate usage.

\section{Acknowledgement}

This research received a partial thesis research grant for graduate students from the Graduate College at King Mongkut's University of Technology, North Bangkok.

\section{$7 \quad$ References}

[1] K. Roger and H. Enrique Danja (2012) Student Affairs and Services in Higher Education: Global Foundations, Issues and Best Practices. Presented by the International Association of Student Affairs and Services (IASAS). In cooperation with: The United Nations Educational, Scientific and Cultural Organisation (UNESCO).

[2] S. Techakosit and P. Nilsook (2016) The Learning Process of Scientific Imagineering through AR in Order to Enhance STEM Literacy.iJET - Vol 11, No 7, 2016, pp. 57-63. https://doi.org/10.3991/ijet.v11i07.5357

[3] M. Mazaher and S. Mohammad (2012) Information Technology (IT) as An Improvement Tool For Customer Relationship Management (CRM). Procedia - Social and Behavioral Sciences 41 (2012) 59 - 64. https://doi.org/10.1016/j.sbspro.2012.04.008

[4] P. Nilsook and P. Wannapiroon (2014) International distance consulting via web conferencing.iJET - Vol 9, No 4, 2014, pp. 60-64. https://doi.org/10.3991/ijet.v9i4.3736

[5] F. Sanfilippo \& C. Pacchierotti (2018) A Wearable Haptic System for the Health Monitoring of Elderly People in Smart Cities.iJOE - Vol 14, No 08, 2018, pp. 52 - 66.

[6] T. Zhang (2014) The Internet of things Promoting Higher Education Revolution. 2012 Fourth International Conference on Multimedia Information Networking and Security.

[7] Anshu, Luam, Wagner, Ponnurangam, Virgilio (2012) Studying User Footprints in Different Online Social Networks.2012 IEEE/ACM International Conference on Advances in Social Networks Analysis and Mining

[8] D. J. Burnett (2010) Innovation in Student Services: Best Practice and Process Innovation Models and Trends.

[9] Fazel, Moayad, Burak, Melike, and Stephanie (2017) Social Behaviometrics for Personalized Devices in the Internet of things Era. Digital Object Identifier 10.1109/ Access. 2017.2719706.IEEE

[10] D. Michal, \& Thore (2012) Private traits and attributes are predictable from digital records of human behavior.www.pnas.org/cgi/doi/10.1073/pnas.1218772110.

[11] S. Yoosomboon \& P. Piriyasurawong (2017) Design of an Embedded Engineering Learning on Social Cloud Model to Enhance Creative Thinking and Creative Product.iJOE Vol. 13, No. 1, 2017, pp. $33-41$.

[12] J. Yang, Z. Feng, X. Ma \& X. Zhang (2018) Indoor Positioning Method Based on Wireless Signal. iJOE - Vol. 14, No. 10, 2018, pp. 53 - 67. https://doi.org/10.3991/ijoe.v14i10.9303 
[13] S. Fan, P. Li, T. Liu, Y. Chen (2015) Population Behavior Analysis of Chinese University Students via Digital Campus Cards. 2015 IEEE 15th International Conference on Data Mining Workshops.

[14] A. Hrnji (2015) the transformation of higher education: evaluation of CRM concept application and its impact on student satisfaction. Eurasia Business and Economics Society 2015.

[15] K. Kongsakun, T. Chanakul \& C.C. Fung (2012) Decision Tree Modeling for an Intelligent Recommendation System Supporting SRM for Universities in Thailand. International Conference on Computer and Information Technology (ICCIT'2012) June 16-17, 2012, Bangkok.

[16] M. B. Piedade \& M. Y. Santos (2008) Student Relationship Management: Concept, Practice and Technological Support. IEEE 2008

[17] Lubov, Ina, Michael (2014) Requirements Analysis for a Student relationship management system - Results from an Empirical Study in Ivy League Universities.45th Hawaii International Conference on System Sciences, IEEE 2012

[18] Hamed, Muhamad Zameri, Safian, Norhayati (2013) A CRM strategic leadership towards sustainable development in student relationship management: SD in higher education. Procedia Manufacturing 2 (2015) 51 - 60. https://doi.org/10.1016/j.promfg.2015.07.010

[19] H. Alqahtani \& H. Al-Sakran (2016) Towards Safe Commuting: Using Internet of things For Building Smart Student Tracking System. International Journal of Advanced Research in Computer Science and Software Engineering. Volume 6, Issue 11, November 2016.

[20] Smart With Gartner. Gartner's Top 10 Strategic Technology Trends for 2017 [Online] Available:https://www.gartner.com/smarterwithgartner/gartners-top-10-technology-trends2017/ [Accessed June 2018].

[21] S. Li, L. D. Xu, S.Zhao (2015) The Internet of things: a survey. Springer Science + Business Media New York 2014. https://doi.org/10.1007/s10796-014-9492-7

[22] Razali , Tomari and Norzali Hj. Mohd (2010) Fusion of Radio Frequency Identification (RFID) and Fingerprint in Boarding School Monitoring System (BoSs).Sustainable Radio Frequency Identification Solutions, Book edited by: Cristina Turcu

[23] Shashank, Shailee, Pooja CHECK NAMES (2013) RFID Based Attendance Management System. International Journal of Electrical and Computer Engineering (IJECE).Vol. 3, No. 6, December 2013, pp. 784 790.

[24] A white paper by the GSMA (2014) A Guide to Bluetooth Beacons. September 2014

[25] D. Deugo (2016) Using Beacons for Attendance Tracking. Int'l Conf. Frontiers in Education: CS and CE.FECS'16

[26] Rui, Gabriella, Peilin, Xia and Andrew (2015) SmartGPA: How Smartphones Can Assess and Predict Academic Performance of College Students. UbiComp '15, September 07-11, 2015, Osaka, Japan c 2015 ACM. ISBN 978-1-4503-3574-4/15/09.

[27] Rui, Fanglin, Zhenyu, Tianxing, Gabriella, Stefanie, Xia, Dror and Andrew (2014) Student Life: Assessing Mental Health, Academic Performance and Behavioral Trends of College Students using Smartphones. Ubicomp '14, September 13 - 17 2014, Seattle, WA, USA Copyright 2014 ACM 978-1-4503-2968-2/14/09

[28] A. R. Arakerimath \& P. K. Gupta (2015) Digital Footprint: Pros, Cons, and Future. Volume IV, Issue X, October 2015 IJLTEMAS ISSN 2278 - 2540

[29] T. Fish (2009) My Digital Footprint: A two-sided digital business model where your privacy will be someone else's business.

[30] D. Zhang, B. Guo, B. Li, and Z. Yu (2010) Extracting Social and Community Intelligence From Digital Footprints: An Emerging Research Area. Z. Yu et al. (Eds.): UIC 2010, LNCS 6406, pp. 4-18, 2010. (C) Springer-Verlag Berlin Heidelberg 2010. 
[31] P. Scanlon (2016) Identifying the Impact of Friends on their Peers Academic Performance. 2016 IEEE/ACM International Conference on Advances in Social Networks Analysis and Mining (ASONAM). https://doi.org/10.1109/ASONAM.2016.7752416

[32] Z. S. Zubi \& M. S. E. Raiani (2014) Using Web Logs Dataset via Web Mining For User Behavior Understanding. International Journal of Computers and communications Volume 8, 2014.

[33] Iqbal, Muhammad, Alan, Jun (2016) Evidence-Based Behavioral Model for Calendar Schedules of Individual Mobile Phone Users.2016 IEEE International Conference on Data Science and Advanced Analytics. CHECK AUTHORS NAMES

[34] M. Jonice \& M. Jano (2007) Customer Relationship Management in Universities and Research Centres. Proceedings of the 2007 11th International Conference on Computer Supported Cooperative Work in Design.

[35] Jirapong, Sakchai (2014) Development of a Graduate Level Student Relationship Management Model.NCCIT2014.The Tenth National Conference on Computing and Information Technology.

[36] Sahoo (2012) A Rfid Based Attendance Tracking System.IOSR Journal Of Environmental Science, Toxicology and Food Technology (IOSR-JESTFT) ISSN: 2319-2402, ISBN: 2319 -2399. Volume 2, Issue 2 (Nov. - Dec. 2012), PP 12-17.

[37] Srinivas, Prashanth, Sundaravadanam, Maheshwar, Prasanna and Varalakshmi (2013) MITSAT-An Automated Student Attendance Tracking System using Bluetooth and EyeOS.978-1-4673-5090-7113/\$31.00 @2013 IEEE.

[38] Mboungou (2015) The Reinvention of the Constituent Relationship Management (CRM) System in Higher Education in Africa. International Journal on Communications (IJC) Volume 4, 2015. https://doi.org/10.14355/ijc.2015.04.003

[39] Bozidar, Marijana, Zorica, Aleksandra, Milos (2013) Providing Services for Student Relationship Management on Cloud Computing Infrastructure. TELSIKS 2013. 978-1-47990902-5/13/\$31.00 (C2013 IEEE.

[40] Jitendra, Hyung-il, Meena, Ashish, Danish (2013) A CRM system for Social Media. International World Wide Web Conference Committee (IW3C2).ACM 978-1-4503-2035$1 / 13 / 05$.

[41] Abdul, Jyothi (2013) Web-Server based Student Attendance System using RFID Technology. International Journal of Engineering Trends and Technology (IJETT) - Volume 4 Issue 5 - May 2013.

\section{Authors}

Nualsi Songsom is a PhD candidate in the Information and Communication Technology for Education, Faculty of Technical Education, King Mongkut's University of Technology North Bangkok (KMUTNB), Bangkok, Thailand. Her research interests focus on student relationship management, internet of things, and digital footprints.

Prachyanun Nilsook is an associate professor at the Division of Information and Communication Technology for Education, King Mongkut's University of Technology North Bangkok (KMUTNB), Thailand. He currently works in the field of ICT for education and Vocational Education Technology Research Centre. He is a member of Professional Societies in the Association for Educational Technology of Thailand (AETT). 
Panita Wannapiroon is an associate professor at the Division of Information and Communication Technology for Education, and the Director of Innovation and Technology Management Research Centre (ITMRC), Science and Technology Research Institute (STRI), King Mongkut's University of Technology North Bangkok (KMUTNB), Thailand. Presently, she works in the field of ICT in education.

Article submitted 2019-01-18. Resubmitted 2019-03-01. Final acceptance 2019-03-07. Final version published as submitted by the authors. 